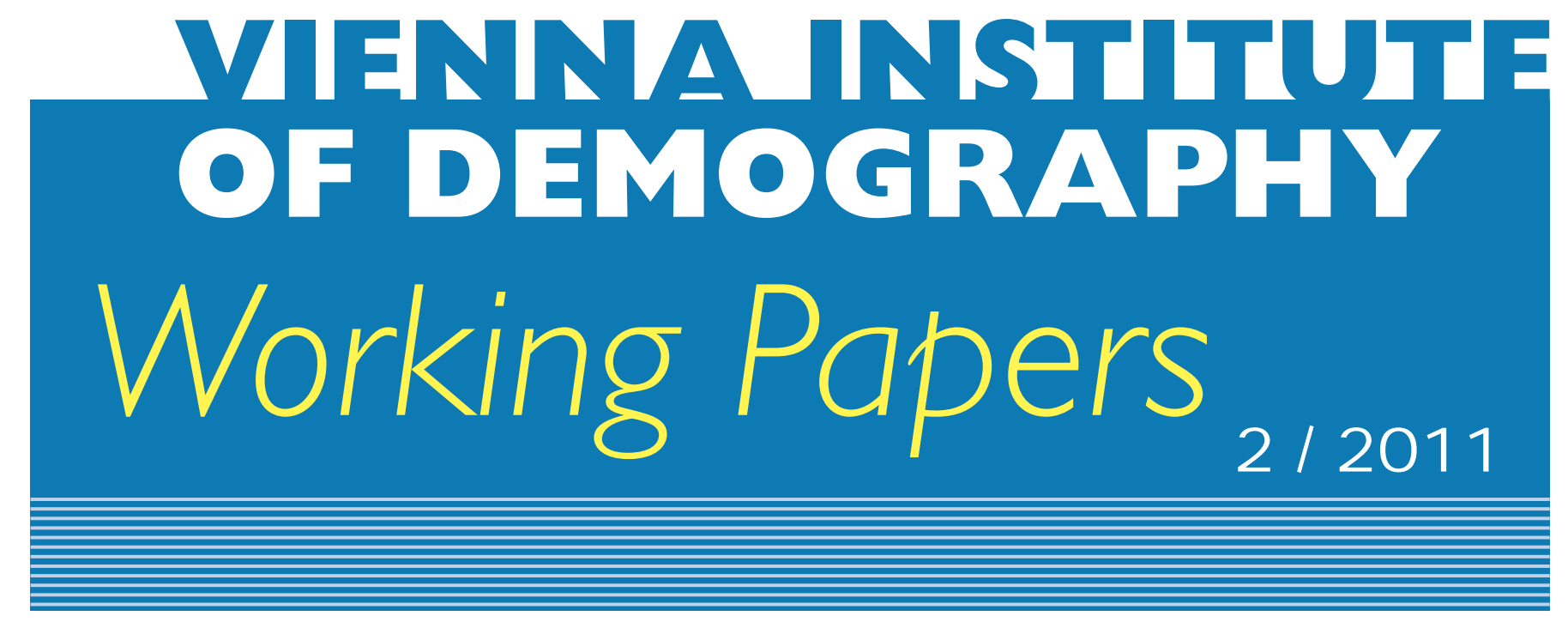

Thomas Fent, Belinda Aparicio Diaz, and Alexia Prskawetz

\title{
Family Policies in the Context of Low Fertility and Social Structure
}

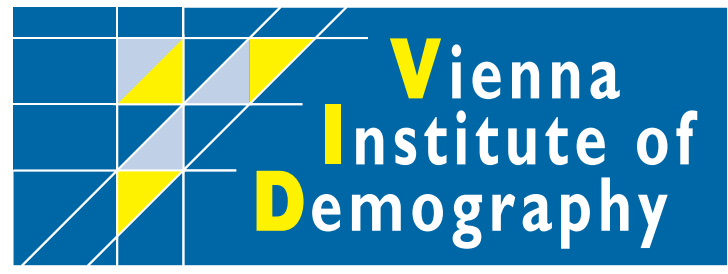

Vienna Institute of Demography Austrian Academy of Sciences

Wohllebengasse 12-14

A-I040Vienna $\cdot$ Austria

E-Mail:vid@oeaw.ac.at

Website: www.oeaw.ac.at/vid 


\begin{abstract}
The aim of this paper is to analyse the effectivity of family policies in the context of different assumptions regarding the social structure of a society. We use an agent based simulation model to analyse the impact of family policies on individual fertility decisions and on cohort fertility, intended fertility, and the fertility gap on the aggregate level. The crucial features of our simulation model are the agents' heterogeneity with respect to age, income, parity, and intended fertility, the social network and social influence. Our results indicate that both fixed and income dependent child supports have a positive and significant impact on fertility. However, several network and social influence parameters have the ability not only to influence fertility itself but also the effectivity of family policies. Therefore, policymakers aiming to transfer a certain policy mix that has proved successful from one country to another one ignoring differences in the social structure may fail. Family policies can only be successful if they explicitly take into account the characteristics of the society they are assigned for.
\end{abstract}

\title{
Keywords
}

Family policies, low fertility, social influence, social networks, social structure.

\section{Authors}

Thomas Fent (corresponding author), Vienna Institute of Demography, Austrian Academy of Sciences; email: thomas.fent@oeaw.ac.at

Belinda Aparicio Diaz, Vienna Institute of Demography, Austrian Academy of Sciences; email: belinda.aparicio.diaz@,oeaw.ac.at

Alexia Prskawetz, Institute of Mathematical Methods in Economics (research group on economics), Vienna University of Technology, and Vienna Institute of Demography, Austrian Academy of Sciences; email: afp@econ.tuwien.ac.at

\section{Acknowledgments}

We would like to thank Isabella Buber-Ennser for helping us with the GGS data. The Austrian GGS was conducted by Statistics Austria with the financial support of the Federal Ministry of Economy, Family and Youth, the Federal Ministry of Science and Research and the Federal Ministry of Labour, Social Affairs and Consumer Protection. The international GGS templates (survey instruments, sample design) were adapted to the Austrian context by the Vienna Institute of Demography and the Austrian Institute for Family Studies. The Austrian Institute for Family Studies has also coordinated the Generations and Gender Programme for Austria. 


\title{
Family Policies in the Context of Low Fertility and Social Structure
}

\author{
Thomas Fent, Belinda Aparicio Diaz, Alexia Prskawetz
}

\section{Introduction}

Many countries of the Western world have witnessed below replacement fertility and fertility rates falling to ever lower levels during the 1980s and 1990s. Despite the slight increases recently observed in several countries (Myrskylä et al., 2008; Goldstein et al., 2009), the continuation of current fertility trends may lead to population shrinkage and ageing in the long run. Consequently, governments are increasingly concerned to adapt family policies targeted towards possible causes underlying these trends. Yet, there is no broad consensus on the effectivity of policies with respect to a sustainable increase or at least stabilisation of fertility.

Assessing data from 22 industrialised countries over the period 1970-1990, Gauthier and Hatzius (1997) find that cash benefits in the form of family allowances are positively related to fertility. McDonald (2006), on the other hand, claims that pronatalist policies are both expensive and ineffective. Investigating swedish data, Björklund (2006) finds that the extension of family policies from the mid-1960s to around 1980 raised the level of fertility. Gauthier (2007), trying to generalise empirical findings in a comprehensive survey, concludes that studies using micro level data often find a positive impact of parental and maternity leave schemes on completed cohort fertility while studies using macro level data find that family policies influence the timing of births rather than the total number of children. Albeit she infers that the impact tends to be small and varies highly depending on the type of data used and on the type of policies. Using data from high-income countries in Europe and North America, Feyrer et al. (2008) find that a doubling of spending is associated with an increase in the fertility rate of 0.15 children.

Many empirical studies on the effectivity of family policies suffer from a static concept of cause and effect disregarding the indirect effect of family policies exerted via social influence mechanisms. Moreover, studies comparing the impact of family policies in different countries often ignore differences in the societal structure in the countries under consideration. This is surprising since the literature on fertility has identified social networks as a key mechanism explaining fertility intentions. Kohler et al. (2002) indicate demographic distortions of period fertility 
measures, economic and social changes, social interaction processes, institutional changes, and postponement-quantum interactions as the main causes of low fertility in Europe. Social interactions like personal communication about fertility intentions or perceived social norms and social pressure may influence childbearing decisions (Bernardi, 2003; Fernandez and Fogli, 2006). Moreover, social networks may not only influence individual childbearing preferences but also individual feasibility of realising these preferences due to the provision of resources like informal childcare, emotional assistance, and material support (Bühler and Philipov, 2005; Philipov et al., 2006).

With this contribution we aim to resolve the confusion and disagreement about the effectivity of family policies by explicitly adressing their twofold impact. We integrate the role of social structure in a model of fertility decisions and investigate whether and to what extent the effectivity of family policies will change under such a framework. More specifically, family policies may have a direct and an indirect effect on fertility. The direct effect easens the burden of having children for instance by providing institutional childcare or financial benefits and allows parents to fulfill their intended fertility. The indirect effect of family policies rests on the assumption that many people imitate or consult their friends, siblings, or parents in choosing their intended fertility. Hence, any additional birth resulting from family policies may cause an increase of fertility intentions within the involved peer group. Policies causing a modest effect on fertility at the individual level may have a large impact at the macro level due to such peer effects (Feyrer et al., 2008).

Family policies can affect fertility through their influence on the costs of children, on individuals' income, and on preferences. Most governments nowadays refrain from universal cash benefits and rather aim to reduce the structural barriers of combining work and childcare. Individuals differ in their needs, tastes, and objectives but public policy makers face the challenge to establish a uniform set of policies to serve a heterogeneous population. Neither the micro nor the macro level alone may explain the influence of family policies (imposed on the macro level) on individual childbearing decisions (taken at the micro level) and the resulting period and cohort fertility patterns (observed on the macro level) to its full extent. Modelling the impact of family policies on fertility decisions requires to include the decision mechanism at the micro level, the society at the macro level, the interaction between the micro and macro level, and the interaction among individuals within their peer groups.

Therefore, we apply an agent based model (ABM) to evaluate the impact of alternative family policies on fertility in the context of social and institutional structures which differ across countries. ABMs offer the opportunity to capture individual heterogeneity with respect to several characteristics and allow us to test hypotheses regarding fertility behaviour in the context of different cultures and different types of family policies. While the focus is on the aggregate level (completed fertility), our model is based on the micro level and explains how aggregate level properties emerge from the behaviour of the agents on the micro level. As the recent literature argues for social interaction as a key factor in shaping fertility decisions and preferences, we explicitly account for peer group effects in our model. Recently ABMs 
have been applied in demography to explain mate choice and marriage bevaviour (Simao and Todd, 2003; Todd and Billari, 2003; Todd et al., 2005; Billari et al., 2007), fertility rates (Aparicio Diaz et al., 2007), and migration patterns. Baroni et al. (2009) apply ABMs to investigate the role of family policies in Sweden.

The paper is organised as follows. In section two we present the model structure, in section three we illustrate the numerical findings, and section four concludes.

\section{The model}

In this section we develop an agent based computational model to investigate how the social structure influences the effectivity of family policies. In particular we study the impact of fixed and income dependent family allowances on individual fertility decisions and the resulting cohort fertility, intended fertility, and fertility gap (the difference between intended fertility and actual fertility) on the aggregate level. We consider a one-sex model containing only female agents. The crucial features of our agent based simulation model are the agents' heterogeneity with respect to age, income, parity, and intended fertility, the social network which links the agents to a small subset of the population and the influence mechanism acting via that network. ${ }^{1}$ The explicit modelling of the social network and social influence mechanims provides the opportunity to capture the direct and the indirect effect of family policies. Although we refer to Austrian data to calibrate our model, our framework and focus is more general. Our aim is to get general insights into the impact of family policies on fertility under different assumptions regarding the social structure of a society rather than accurately predicting the increase of fertility due to a certain set of policy measures.

\subsection{Initial population}

At time $t$ each agent $i$ is characterised by her age $x_{i, t}$, household income $w_{i, t}$, parity $p_{i, t}$, the number of her dependent children (who do not yet have their own income) $n_{i, t}$, and her intended fertility $f_{i, t}$. We use Austrian census data to obtain an initial age and parity distribution. The parity distribution and the distribution of the age of the children is based on Austrian data on age at birth in $2008^{2}$. Moreover, we apply data from the Austrian income tax statistics ${ }^{3}$ for the distribution of household income. We use age-specific data on the $25 \%$ quantile, the median value, and the $75 \%$ quantile of the annual net income and interpolate the data. Agents get assigned a value $z_{i}$ determining the quantile in the age specific income distribution they belong

\footnotetext{
${ }^{1}$ We are aware that other characteristics like for instance education also have an impact on childbearing behaviour. However, we refrain from including additional characteristics since this would come at the cost of additional model complexity without gaining any further insights with respect to the impact of the social structure on the effectivity of family policies. Moreover, education is highly correlated with income. Therefore, if we include both, income and education, it will be difficult to disentangle the impact of the two.

${ }^{2}$ STATISTIK AUSTRIA, Statistik der natürlichen Bevölkerungsbewegung 2008

${ }^{3}$ STATISTIK AUSTRIA, Allgemeiner Einkommensbericht 2008
} 
to. Due to simplicity we assume that agents remain in the same quantile during their entire life but progress to higher income levels as they age. Then we use data from the Austrian Gender and Generation Survey (GGS) to estimate the distribution of the desire for additional children given the agents age and parity. We define the probability $\pi_{i}^{m}$ that agent $i$ wants at least $m$ additional children $(1 \leq m \leq 8)$ and use the logit model

$$
\operatorname{logit}\left(\pi_{i}^{m}\right)=\beta_{0}^{m}+\beta_{1}^{m} x_{i}+\beta_{2}^{m} p_{i}
$$

for each $m$ to estimate the according probabilities from the GGS data for our initial population.

\section{$2.2 \quad$ Simulation steps}

The agents own consumption, $c_{i, t}$, is assumed to be a concave function of the household income,

$$
c_{i, t}=\sigma \sqrt{w_{i, t}}
$$

and the consumption level of $n_{i, t}$ dependent children is defined as ${ }^{4}$

$$
c_{i, t}^{\left(n_{i, t}\right)}=n_{i, t} \tau \sqrt{w_{i, t}} .
$$

Therefore, the disposable income $y_{i, t}$ - the difference between household income $w_{i, t}$ and expenditures for consumption-becomes

$$
y_{i, t}=w_{i, t}-c_{i, t}-c_{i, t}^{\left(n_{i, t}\right)}
$$

If the intended fertility exceeds the actual parity,

$$
f_{i, t}>p_{i, t}
$$

and the disposable income is equal or greater than the estimated costs of an additional child,

$$
y_{i, t} \geq \tau \sqrt{w_{i, t}} \Longleftrightarrow \sqrt{w_{i, t}} \geq \sigma+\left(n_{i, t}+1\right) \tau,
$$

the agent is exposed to the biological probability (fecundity) of having another child (Leridon, 2004, 2008). In case of a successful live birth a new agent is generated with a probability depending on the Austrian sex ratio at birth since our simulation only keeps track of female individuals. This new agent $k$ with age $x_{k, t}=0$ is mutually linked to her mother and her sisters (see subsection 2.4). Male children are not implemented as agents within the artificial population but they contribute to the parity and the number of dependent children of their mother.

Each time step each agent ages by one year, $x_{i, t+1}=x_{i, t}+1$ and, therefore, children will eventually turn adults earning their own income. The probability of this transition depends on the agents age and is based on age specific labour force

\footnotetext{
${ }^{4}$ We do not model the quantity-quality trade-off of children explicity but we assume that the spendings for children increase with household income.
} 
participation rates observed in Austria in $2008^{5}$. After the child's transition to adulthood the number of dependent children of her mother is reduced by one but leaving her mothers parity unchanged. Moreover, the new adult agent gets assigned her own income level $z_{i}$ determining her household income $w_{i, t}=w_{i, t}\left(z_{i}, x_{i, t}\right)$, her own social network (see subsection 2.4), and her own fertility intentions. Thereafter she starts to evaluate her fertility intentions according to the inequalities (2) and (3). Finally, agents die off with a probability according to the Austrian female life table.

Since the distribution of fertility preferences in the artificial society may have changed since the initialisation, we compute for each $m$ the aggregate share of adult agents with parity $p_{i}<m$ who desire at least $m$ children, $\Pi_{t}^{m}$. We use these shares to update the parameters $\beta_{0}^{m}$ in equation (1) every five years according to

$$
\beta_{0, t}^{m}=\beta_{0}^{m} \frac{\log \frac{\Pi_{t}^{m}}{1-\Pi_{t}^{m}}}{\log \frac{\Pi_{0}^{m}}{1-\Pi_{0}^{m}}},
$$

and the new adult agents intended fertility is assigned according to the probabilities

$$
\pi_{i}^{m}=\frac{\exp \left(\beta_{0, t}^{m}+\beta_{1}^{m} x_{i}\right)}{1+\exp \left(\beta_{0, t}^{m}+\beta_{1}^{m} x_{i}\right)}
$$

\subsection{Impact of family policies}

We investigate two alternative types of family policies. The policy maker may provide a fixed amount $b^{f}$ per child to each household or a benefit proportional to the household income $w_{i, t}{ }^{6}$. A fixed child support partially covers the consumption level of $n_{i, t}$ dependent children,

$$
c_{i, t}^{\left(n_{i, t}\right)}=n_{i, t}\left(\tau \sqrt{w_{i, t}}-b^{f}\right)
$$

and the disposable income can be expressed as

$$
y_{i, t}=w_{i, t}-\sigma \sqrt{w_{i, t}}-n_{i, t}\left(\tau \sqrt{w_{i, t}}-b^{f}\right) .
$$

The necessary condition for having an additional child becomes

$$
\sqrt{w_{i, t}} \geq \sigma+\left(n_{i, t}+1\right)\left(\tau-\frac{b^{f}}{\sqrt{w_{i, t}}}\right)
$$

In case of a proportional cash benefit the consumption costs of $n_{i, t}$ dependent children become

$$
c_{i, t}^{\left(n_{i, t}\right)}=n_{i, t}\left(\tau \sqrt{w_{i, t}}-b^{v} w_{i, t}\right)
$$

\footnotetext{
${ }^{5}$ STATISTIK AUSTRIA, Mikrozensus-Arbeitskräfteerhebung 2008

${ }^{6}$ Although in our mathematical notation family policies appear as cash benefits, this approach is perfectly capable to capture non-monetary family policies in terms of their monetary equivalent. For instance publicly subsidised childcare is equivalent to an income dependent policy since households with higher income gain more.
} 
and the disposable income can be expressed as

$$
y_{i, t}=w_{i, t}-\sigma \sqrt{w_{i, t}}-n_{i, t}\left(\tau \sqrt{w_{i, t}}-b^{v} w_{i, t}\right)
$$

resulting in the necessary condition for having an additional child

$$
\sqrt{w_{i, t}} \geq \sigma+\left(n_{i, t}+1\right)\left(\tau-b^{v} \sqrt{w_{i, t}}\right) .
$$

Finally, if the policy maker opts for a policy mix combining fixed and income dependent cash benefits, the necessary condition is

$$
\sqrt{w_{i, t}} \geq \sigma+\left(n_{i, t}+1\right)\left(\tau-\frac{b^{f}}{\sqrt{w_{i, t}}}-b^{v} \sqrt{w_{i, t}}\right) .
$$

This inequality embraces the direct effect of family policies, i.e. the alleviation of the budget contraints enabling parents to realise their fertility intentions.

\subsection{Endogenous social network}

The agents are closely linked to a set of other agents with whom they communicate about their fertility intentions and realisations. We refer to this group as an agent's social network or peer group. The similarity of agents' characteristics has an impact on the probability of being chosen into an agents social network. Moreover, we assume a certain degree of network transitivity or clustering, i.e. the tendency that two agents who are connected to a third party establish a mutual relationship over time (the friends of my friends are also my friends). We consider age, income, and intended fertility as those characteristics determining an agent's social background and compute the social distance between agents $i$ and $j$,

$$
d_{i j}=\left|x_{i}-x_{j}\right|+\epsilon\left|z_{i}-z_{j}\right|+\epsilon_{2}\left|f_{i}-f_{j}\right| .
$$

The parameter $\epsilon$ determines the weight of the income difference and $\epsilon_{2}$ determines the weight of the differences in intended fertility of the two agents. Differences in income or intended fertility are ignored when setting the respective parameter 0 . To build up the social network an agent chooses a distance $d$ with probability

$$
p r_{1}(d)=c \exp (-\alpha d)
$$

and then picks an agent with distance $d$ as a new friend. For this choice we define another probability $p r_{2}$ determining whether this new friend is chosen among those individuals who are not linked to any of the agents peers or only among those individuals who are linked to at least one of the agents friends. This parameter allows us to adjust the degree of transitivity in the social network. The constant $c$ is a normalisation parameter to make sure that the probabilities of all feasible distances sum up to one and the parameter $\alpha$ determines the agent's level of homophily. If $\alpha$ is assigned high values, the chance of a connection between similar individuals becomes high. The selecting agent is also added to the network of the selected agent. Thus, we assume a mutual friendship relation which means that the underlying network topology is represented by an undirected graph. This procedure is repeated until the desired number of peers, $s$, is found. This desired network size is drawn from a log-normal distribution (see for instance Dunbar and Spoors, 1995, Fig. 1) with mean $\bar{s}$ and rounded to the nearest integer. 


\subsection{Social influence and intended fertility}

At each time $t$ each agent $i$ has an intended fertility $f_{i, t}$, defined as the sum of current parity $p_{i, t}$ and the intended additional children, which must be integer and nonnegative. The intended fertility may be altered due to social influence imposed by the peer group. To model the social influence on fertility intentions we adapt an approach suggested by Goldenberg et al. (2007). We assume that with probability $p r_{3}\left(p r_{4}\right)$ intended fertility increases (decreases) by one due to the social influence exerted by a peer with parity greater (less) than the agents intended fertility. Then, we compute $\pi_{i}^{+}\left(\pi_{i}^{-}\right)$, the number of agents $j$ who are linked to $i$ and have a parity greater (less) than the intended fertility of agent $i$, i.e. $p_{j, t}>f_{i, t}\left(p_{j, t}<f_{i, t}\right)$. Based on these calculations we compute the probabilities for an agent to be positively or negatively influenced by at least one agent from the peer group ${ }^{7}$,

$$
\begin{aligned}
& p_{i, t}^{+}=1-\left(1-p r_{3}\right)^{\pi_{i}^{+}} \\
& p_{i, t}^{-}=1-\left(1-p r_{4}\right)^{\pi_{i}^{-}} .
\end{aligned}
$$

Individuals may be exposed to positive influence, negative influence, both positive and negative influence, or neither. Hence, the probability of being only positively (negatively) influenced becomes $\left(1-p_{i, t}^{-}\right) p_{i, t}^{+}$(respectively $\left.\left(1-p_{i, t}^{+}\right) p_{i, t}^{-}\right)$and the probabiliy of being positively and negatively influenced is $p_{i, t}^{+} p_{i, t}^{-}$. We use the parameter $\gamma$ $(1-\gamma)$ to determine the fraction of individuals who increase (decrease) their intended fertility in case of mixed influence. Then, the probabilities to increase, decrease, or keep the intended fertility constant are

$$
\begin{aligned}
p_{i}\left(f_{i, t+1}=f_{i, t}+1\right) & =\left(1-p_{i, t}^{-}\right) p_{i, t}^{+}+\gamma p_{i, t}^{+} p_{i, t}^{-} \\
p_{i}\left(f_{i, t+1}=f_{i, t}-1\right) & =\left(1-p_{i, t}^{+}\right) p_{i, t}^{-}+(1-\gamma) p_{i, t}^{+} p_{i, t}^{-} \\
p_{i}\left(f_{i, t+1}=f_{i, t}\right) & =\left(1-p_{i, t}^{+}\right)\left(1-p_{i, t}^{-}\right) .
\end{aligned}
$$

These adaptations of individual fertility intentions capture the indirect effect of family policies. Parents who have additional children because of the direct effect described before may, subsequently, exert a social influence on their peers resulting in an increase of their fertility intentions.

While in the marketing literature adopting a certain product may influence friends to adopt this product as well, in our model actual births are assumed to influence fertility intentions which need not to be realised immediately. Thus, we allow for different probabilities for the increase and decrease since the actual parity within the network is usually lower than the desired fertility of the peers. Using the same probability for increase and decrease results in a steady bias towards lower levels of intended fertility.

\footnotetext{
${ }^{7}$ If $p r_{3}$ is the probability of increasing intended fertility due to meeting one peer with higher parity, then $\left(1-p r_{3}\right)$ is the probability of not increasing intended fertility despite this one peer, $\left(1-p r_{3}\right)^{\pi_{i}^{+}}$is the probability of not increasing intended fertility despite $\pi_{i}^{+}$peers with higher parity, and $1-\left(1-p r_{3}\right)^{\pi_{i}^{+}}$is the probability of increasing intended fertility when being exposed to $\pi_{i}^{+}$peers with higher parity.
} 


\section{Simulation Results}

To explore the simulation model described in the previous section we generate an initial population of agents endowed with the characteristics age, parity, number of dependent children, intended fertility, and income based on Austrian data. Next, we run the simulation model for 100 time steps (years) with a fixed set of parameters and observe completed cohort fertility, intended fertility, and the fertility gap (the difference between intended and completed cohort fertility) on the aggregate level. Afterwards we generate another initial population and run the simulation again with a different set of parameters. Since we are interested in the role of social structure with regard to the impact of family policies we vary the level of fixed and income dependent family allowances $b^{f}$ and $b^{v}$, homophily $\alpha$, the degree of network transitivity $\mathrm{pr}_{2}$, the weight of income $\epsilon_{2}$, and the strength of positive and negative social influence $p r_{3}$ and $p r_{4}$. In particular we use $\epsilon=1, \tau=2.3, \sigma=2.5, \gamma=0.7$, $\alpha=0.2: 0.4: 1.0^{8}, \epsilon_{2}=0: 3: 3, b^{f}=0: 0.2: 2.0, b^{v}=0: 0.04: 0.28$, $p r_{2}=0.1: 0.3: 0.7, p r_{3}=0.16: 0.02: 0.22$, and $p r_{3}-p r_{4}=-0.06: 0.02: 0.06$ which can be interpreted as applying 88 different sets of family policies (determined by the parameters $b^{f}$ and $b^{v}$ ) on 3780 different societies (represented by $\alpha, \epsilon_{2}, p r_{2}$, $p r_{3}$, and $p r_{3}-p r_{4}$ ). To reduce the impact of randomness we repeat the simulations for each parameter set several times resulting in a total of about 1.4 million simulations. In this section we summarise the results obtained from these simulations.

Since actual fertility depends on the realisation of fertility intentions we investigate the two components intended fertility and fertility gap independently. The fertility gap allows us to measure the direct effect of family policies and the comparison of fertility intentions resulting from different policies allows us to measure the indirect effect. Figure 1 depicts completed cohort fertility, intended fertility, and the fertility gap of those birth cohorts finishing their reproductive period during the last ten years of the simulation versus fixed (graphs in the left column) and income dependent (graphs in the right column) child supports. Here and in the following figures the solid red line always represents the average over all simulations and the grey shaded area indicates the range capturing the outcome of $95 \%$ of the simulations. In the left column dashed, dotted, and dotdashed lines in black, green, and blue show the averages over all simulations with the same level of income dependent family allowances $\left(b^{v}\right)$ and in the right column they depict the average over all simulations with the same level of fixed family allowances $\left(b^{f}\right)$. Both, fixed and income dependent family allowances appear to have a positive influence on cohort fertility, a small positive impact on intended fertility and a negative impact on the fertility gap. Since the impact of family policies on the fertility gap appears more pronounced than the impact on intended fertility we may conclude that in our simulation model and for the specific parameter range the direct effect of family policies is stronger than the indirect effect.

Although these graphs motivate conclusions regarding the impact of family policies on fertility it is not clear whether this is just a delusion resulting from

\footnotetext{
${ }^{8}$ This means the parameter $\alpha$ is varied from 0.2 to 1.0 by increments of 0.4
} 

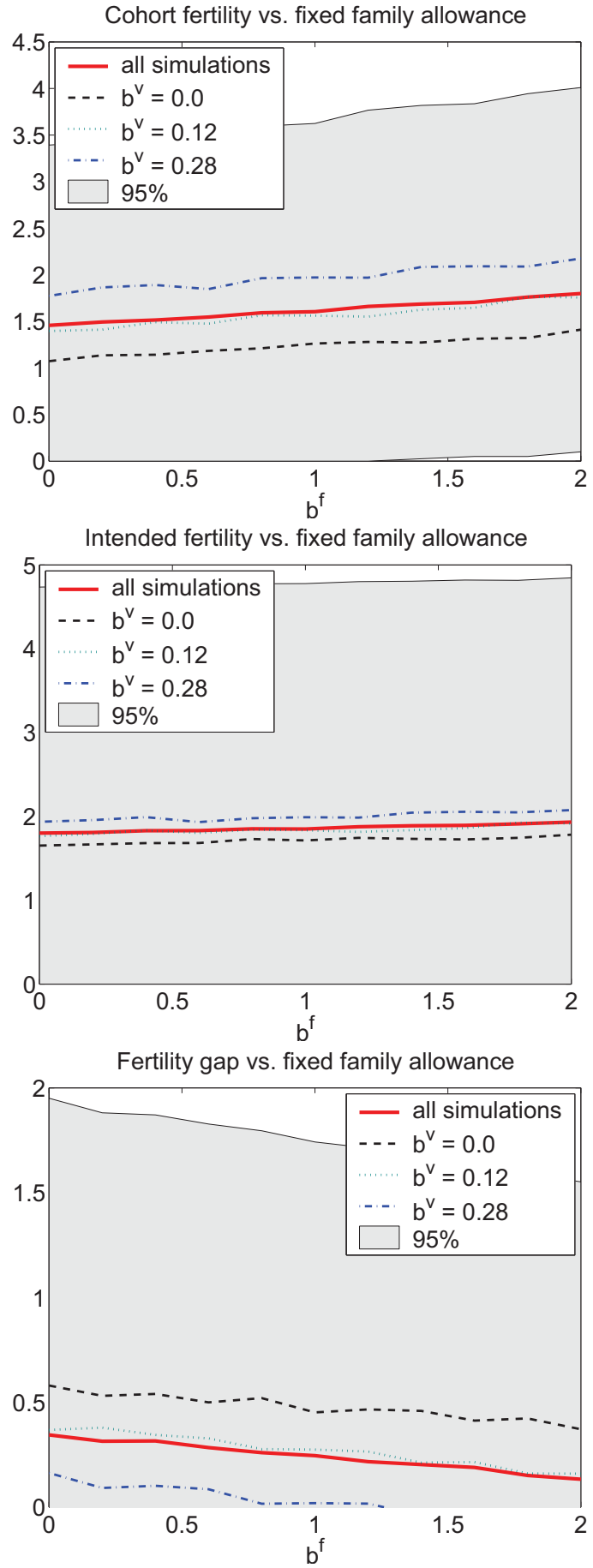

Cohort fertility vs. income dependent family allowance

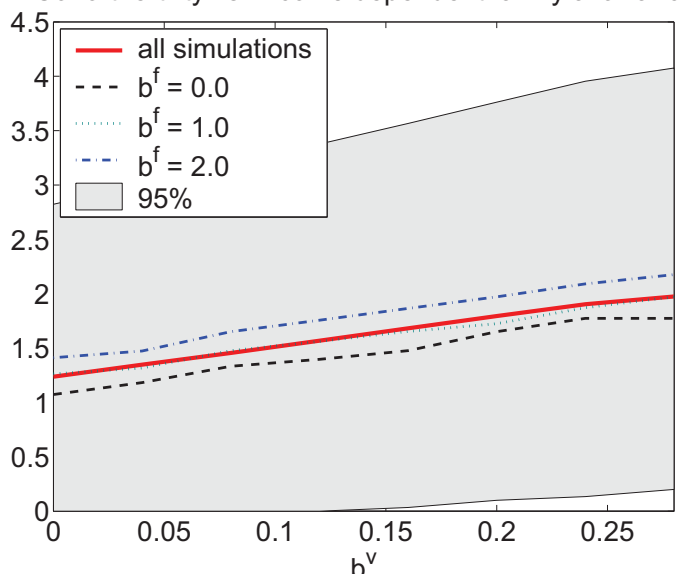

Intended fertility vs. income dependent family allowance

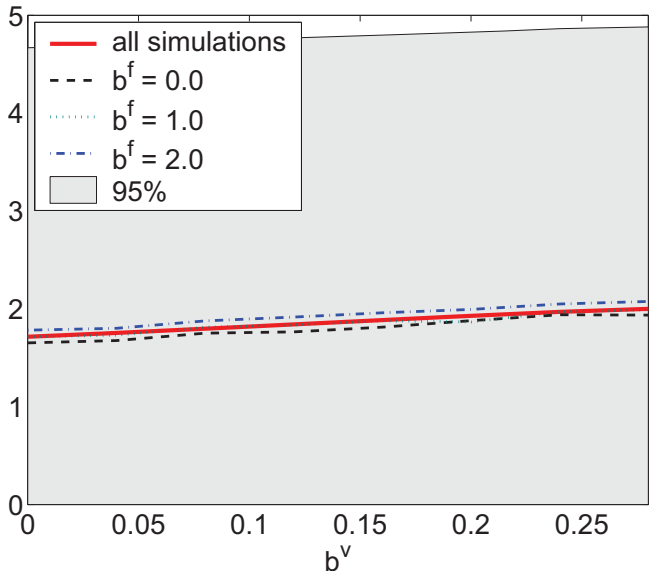

Fertility gap vs. income dependent family allowance

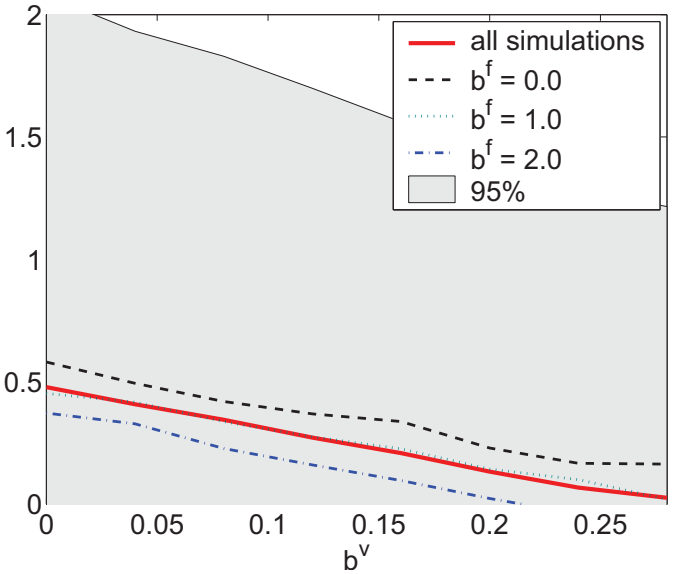

Figure 1: Completed cohort fertility, intended fertility, and fertility gap by fixed, $b^{f}$, and income dependent, $b^{v}$, family allowances. Both types of family allowances have a positive impact on cohort fertility and intended fertility and a negative impact on the fertility gap. 
averaging over many simulation runs. Therefore we present statistical estimates on the impact of child supports in table 1 . The dependent variables are completed cohort fertility (ctfr), intended fertility (f), and the fertility gap (gap) and the explanatory variables are public spending in fixed family allowances (spendingbf) and income dependent family allowances (spendingbv) measured in monetary units per child per year. The regressions confirm that both types of family allowances have a significant

\begin{tabular}{lccc}
\hline $\begin{array}{l}\text { dependent } \\
\text { variable }\end{array}$ & ctfr & $\mathrm{f}$ & gap \\
\hline spendingbf & $.1887161^{* * *}$ & $.0706443^{* * *}$ & $-.1180716^{* * *}$ \\
& $(.0011947)$ & $(.0018359)$ & $(.000757)$ \\
spendingbv & $.0658147^{* * *}$ & $.0309704^{* * *}$ & $-.0348443^{* * *}$ \\
& $(.0001891)$ & $(.0002906)$ & $(.0001198)$ \\
\hline Adjusted $R^{2}$ & 0.0874 & 0.0084 & 0.0663 \\
\hline
\end{tabular}

Table 1: Estimation of the impact of fixed, spendingbf, and income dependent, spendingbv, family allowances on completed cohort fertility, intended fertility, and the fertility gap, standard errors in parentheses, ${ }^{*}$ significant at 10 percent; ${ }^{* *}$ significant at 5 percent; $* * *$ significant at 1 percent.

positive impact on cohort fertility and intended fertility and a significant negative impact on the fertility gap. Fixed family allowances show a stronger impact. The coefficient for spendingbf explaining chohort fertility, .1887161, can be interpreted such that increasing public investments in children by 1000 Euro per child and year would increase cohort fertility by about 0.19 . However, this result should be interpreted with caution since our model is not calibrated to allow for such accurate quantifications.

Figures 2 to 5 again depict cohort fertility, intended fertility and the fertility gap versus fixed an income dependent family allowances. In the left (right) column dashed, dotted, and dotdashed lines represent the averages over simulations with the same level of income dependent family allowances, $b^{v}$ (fixed family allowances, $b^{f}$ ). The colours (black, blue, and green) indicate different combinations of family allowances and agents' homophily (figure 2), weight of intended fertility in choosing the social network (figure 3), network transitivity (figure 4), and the difference between the probabilities of being influenced by peers with higher or lower parity (figure 5). The graphs reveal that homophily $\alpha$, the weight $\epsilon_{2}$, and transitivity $p r_{2}$ have a visible but small impact on fertility but the difference $p r_{3}-p r_{4}$ has a pronounced positive impact on completed cohort fertility and on the fertility gap and an extremely strong positive impact on intended fertility which actually exceeds the impact of the policy mix. Thus, the influence mechanism determined by the parameters $p r_{3}$ and $p r_{4}$ can drastically alter the indirect effect of family policies.

Figure 6 depicts cohort fertility, intended fertility and the fertility gap versus the difference $p r_{3}-p r_{4}$. In the left (right) column the dashed, dotted, and dotdashed lines in black, green, and blue represent the averages over all simulations with the same level of income dependent (fixed) family allowances. These graphs again illustrate the strong positive impact of the difference $p r_{3}-p r_{4}$ on the three 

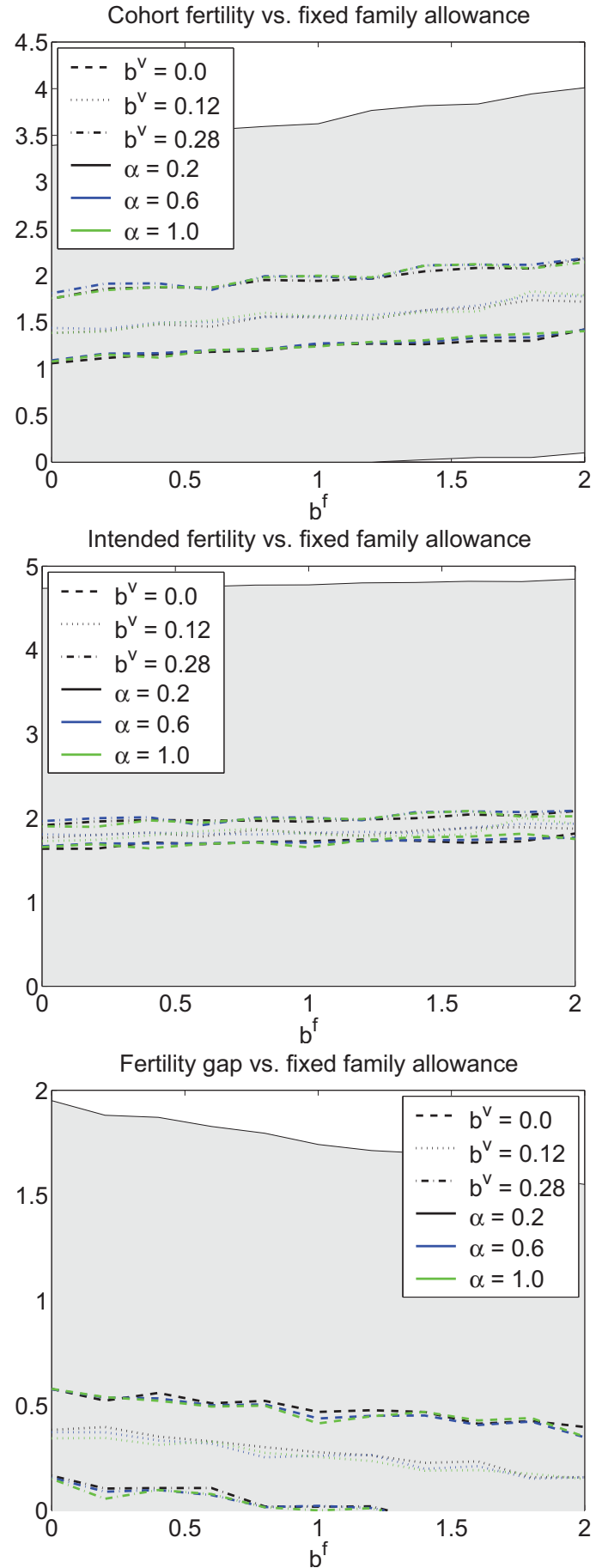

Cohort fertility vs. income dependent family allowance

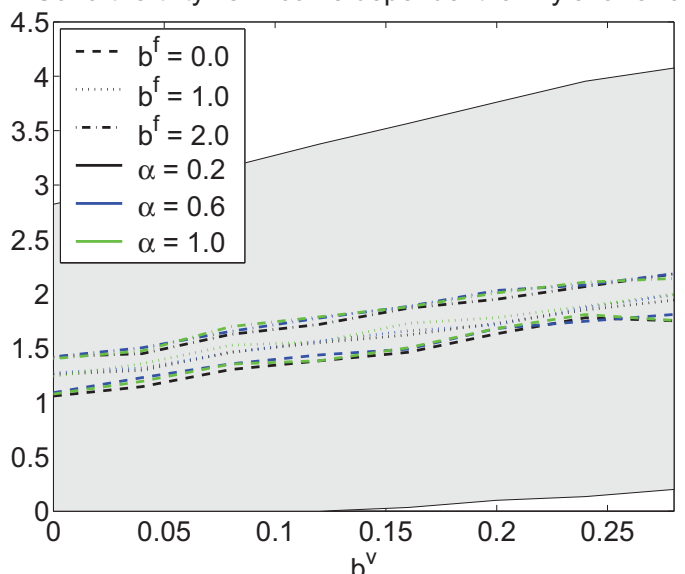

Intended fertility vs. income dependent family allowance

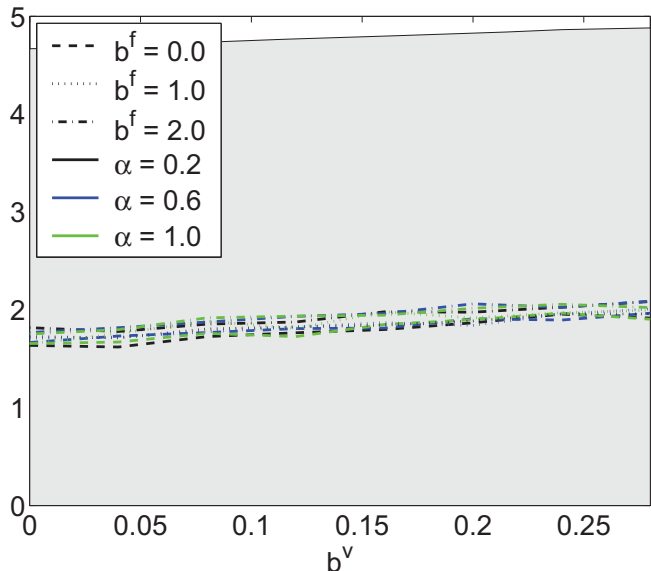

Fertility gap vs. income dependent family allowance

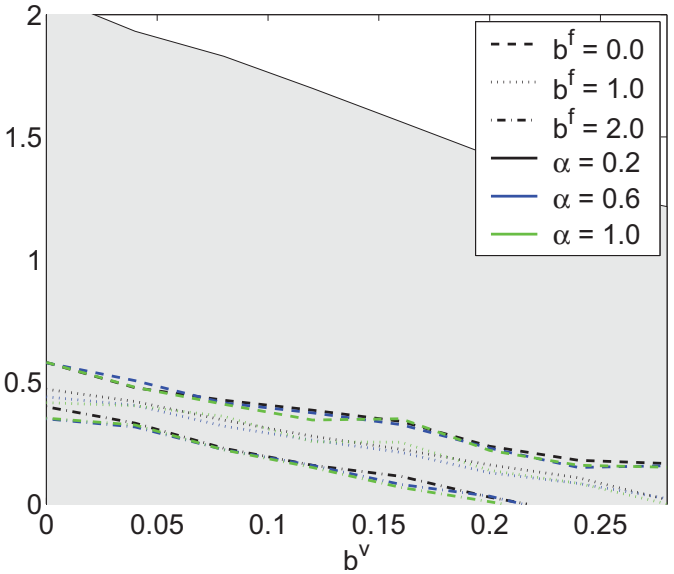

Figure 2: Completed cohort fertility, intended fertility, and fertility gap by fixed, $b^{f}$, and income dependent, $b^{v}$, family allowances and by homphily $\alpha$. Homophily appears to have a positive impact on completed cohort fertility and intended fertility. The overall impact of homphily is small compared to the impact of the policy mix. 

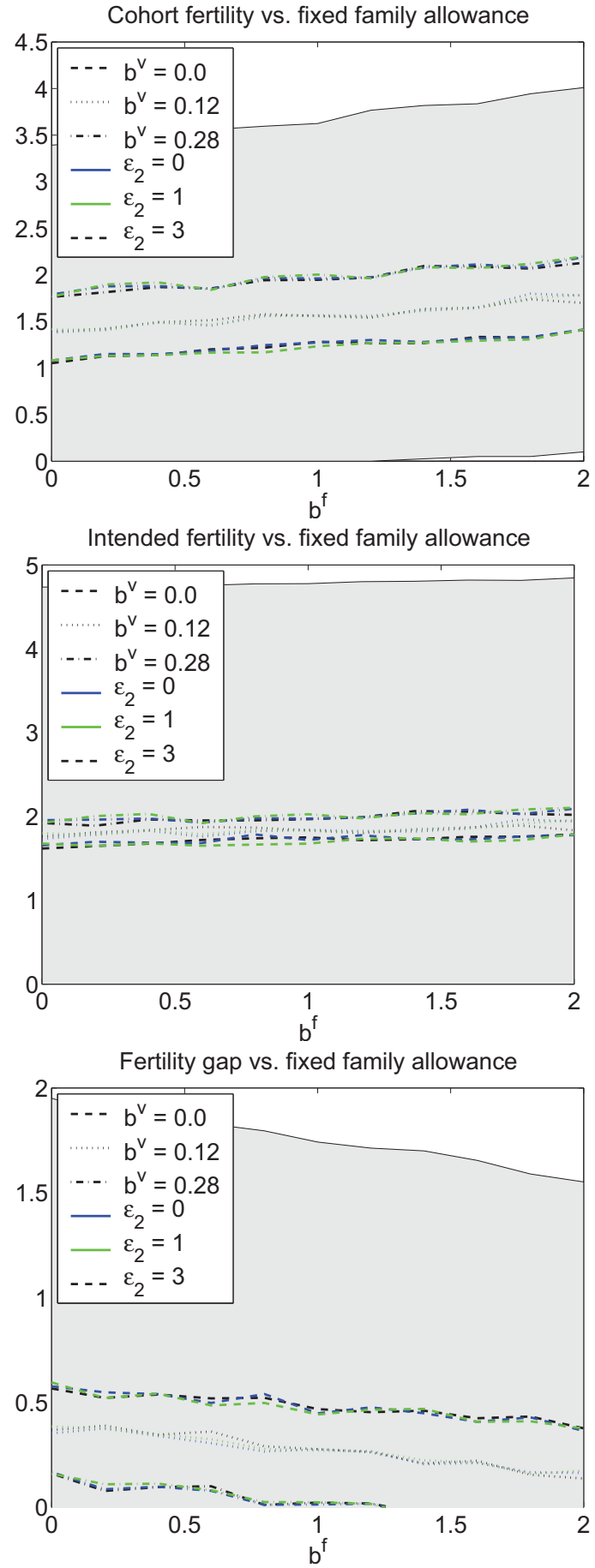

Cohort fertility vs. income dependent family allowance

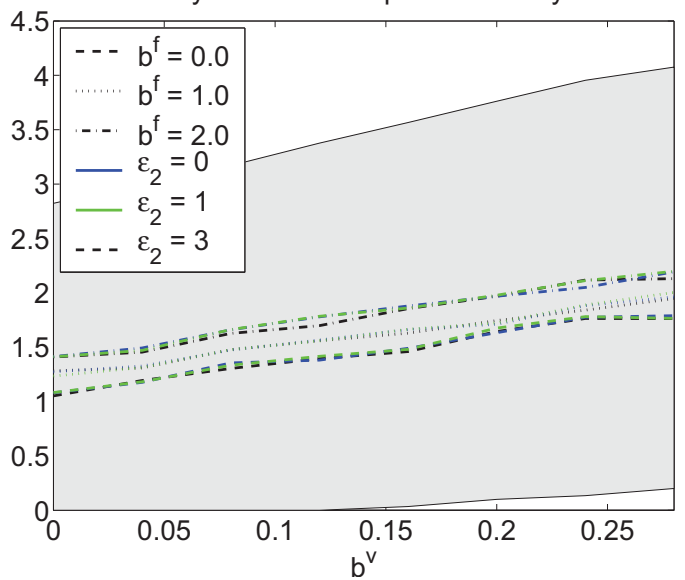

Intended fertility vs. income dependent family allowance

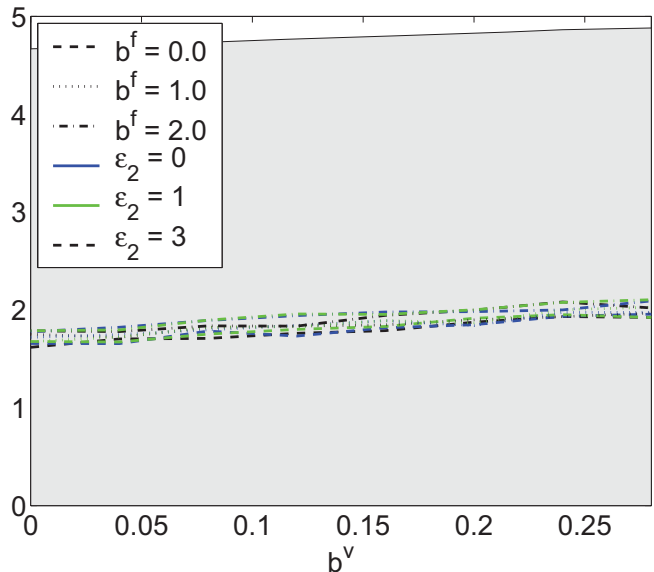

Fertility gap vs. income dependent family allowance

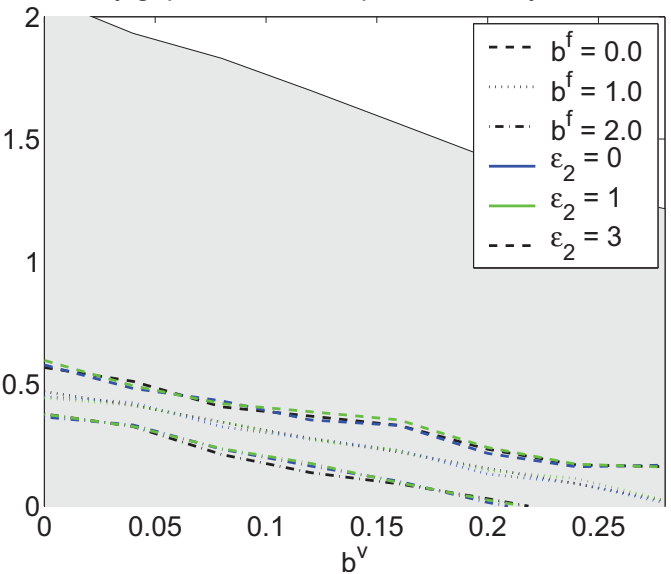

Figure 3: Completed cohort fertility, intended fertility, and fertility gap by fixed, $b^{f}$, and income dependent, $b^{v}$, family allowances and $\epsilon_{2}$, the weight of intended fertility. The weight of intended fertility shows no clear-cut influence. 


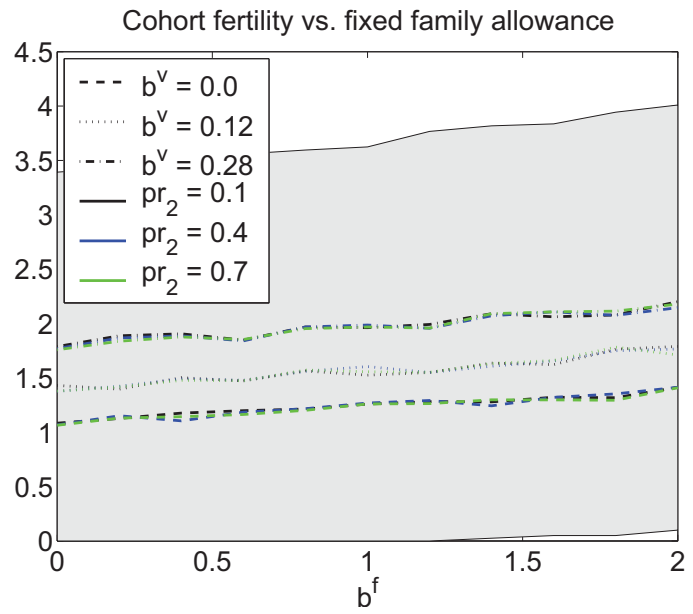

Intended fertility vs. fixed family allowance

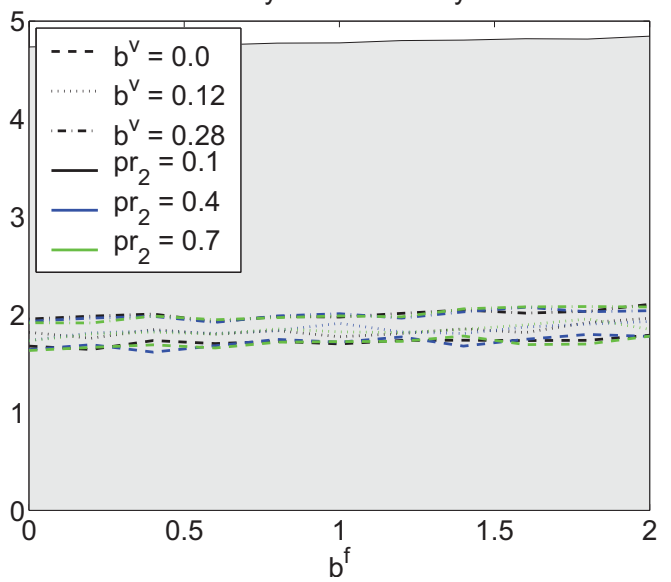

Fertility gap vs. fixed family allowance

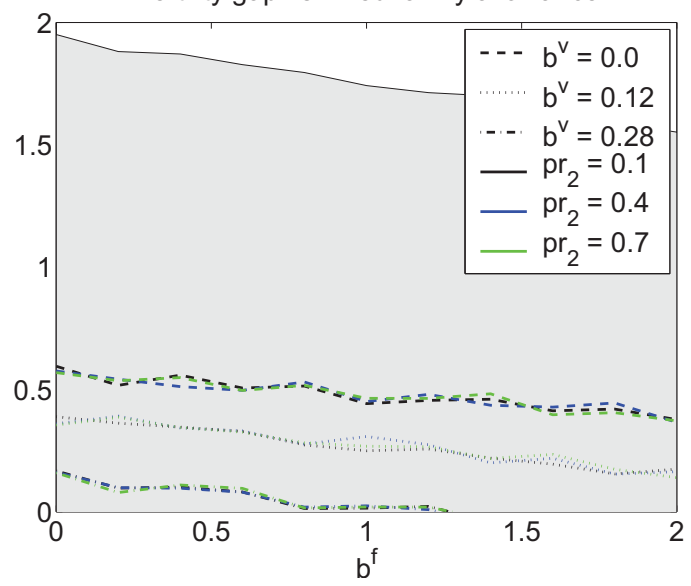

Cohort fertility vs. income dependent family allowance

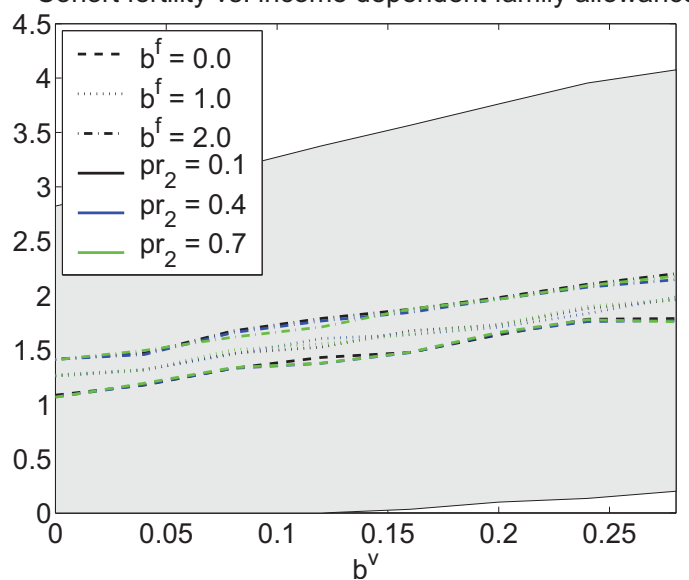

Intended fertility vs. income dependent family allowance

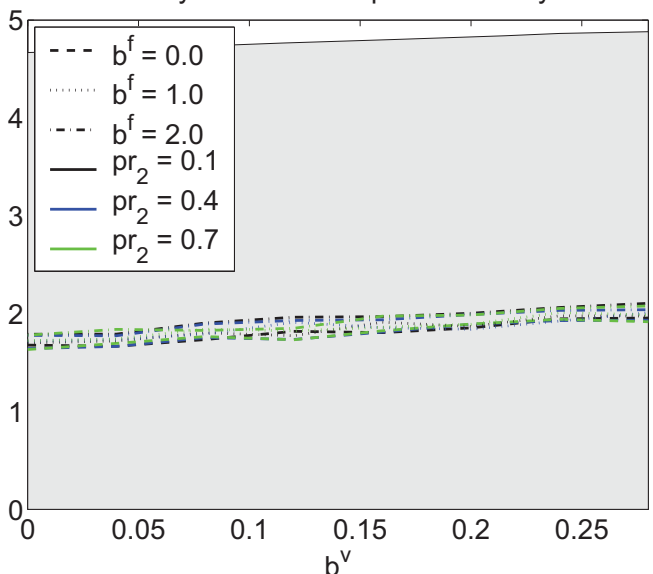

Fertility gap vs. income dependent family allowance

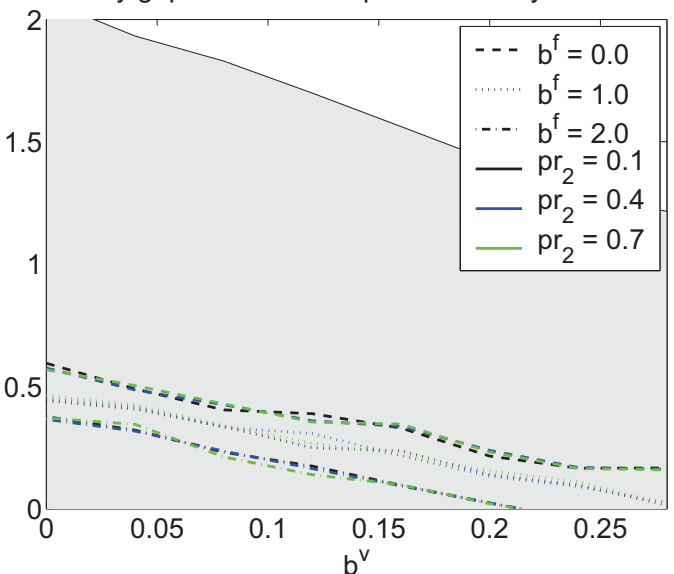

Figure 4: Completed cohort fertility, intended fertility, and fertility gap by fixed, $b^{f}$, and income dependent, $b^{v}$, family allowances and by network transitivity $p r_{2}$. Transitivity shows no clear-cut influence. 

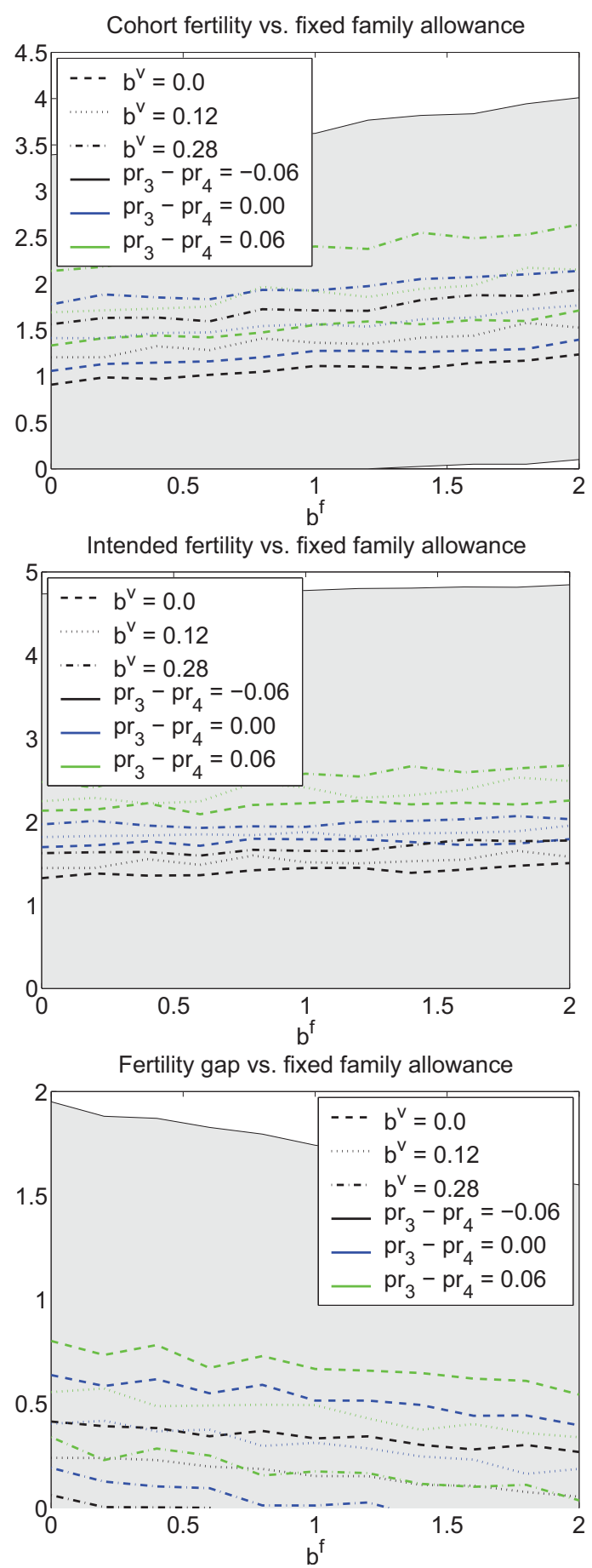

Cohort fertility vs. income dependent family allowance

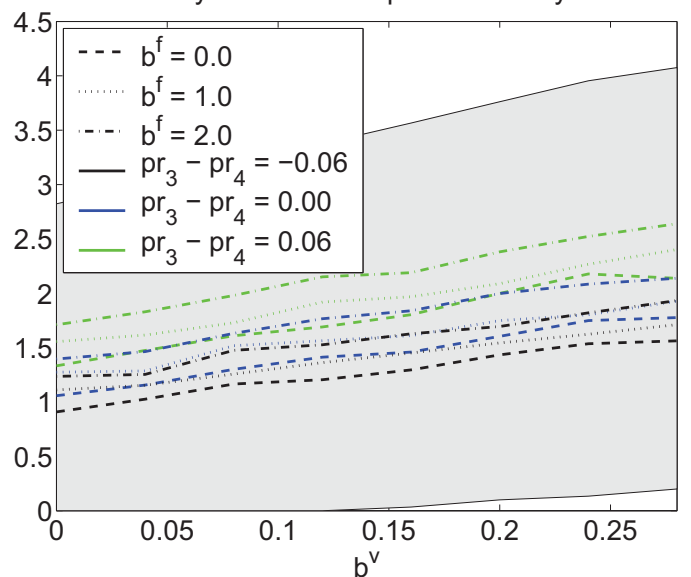

Intended fertility vs. income dependent family allowance

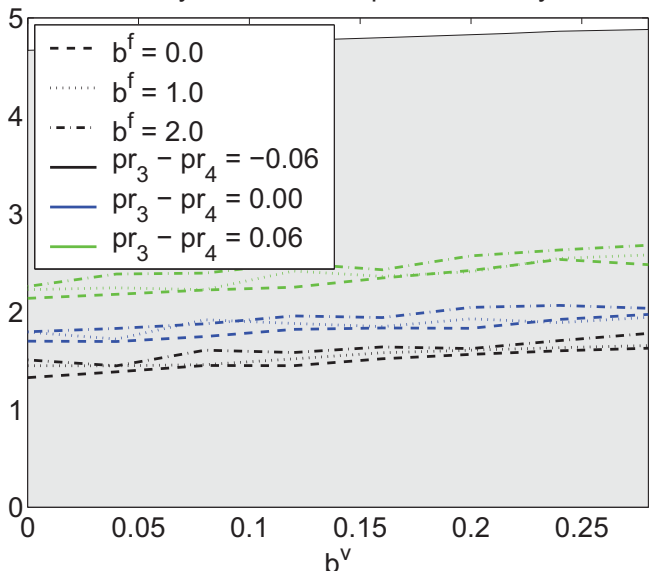

Fertility gap vs. income dependent family allowance

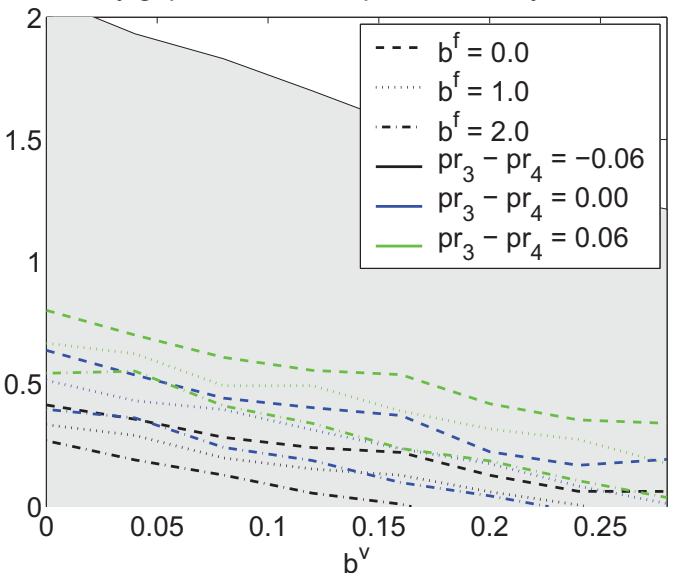

Figure 5: Completed cohort fertility, intended fertility, and fertility gap by fixed, $b^{f}$, and income dependent, $b^{v}$, family allowances and $p r_{3}-p r_{4}$, the difference between the probabilities of positive and negative social influence. The difference has a strong positive impact on completed cohort fertility and on the fertility gap and an extremely strong positive impact on intended fertility which actually exceeds the impact of the policy mix. 
fertility measures. Moreover, the graphs in the second row show that $p r_{3}-p r_{4}$ has a strong impact on the indirect effect of family policies exceeding the impact of the policy mix (because the range of intended fertility captured by each of the curves is bigger than the gap between the curves). The graph in the left panel of the third row shows that the impact of income dependent family allowances on the direct effect is stronger than the impact of $p r_{3}-p r_{4}$ (because the gap between the curves is bigger than the range captured by each curve). The graph in the right panel of the third row shows that the impacts of fixed family allowances and $p r_{3}-p r_{4}$ on the direct effect are approximately equal. Finally, all six graphs in this figure reveal a nonlinear impact of $p r_{3}-p r_{4}$. We will consider this nonlinearity in the following statistical investigation.

In table 2 we present statistical estimates on the impact of child supports on fertility controlling for network parameters and for the social influence. Again, the dependent variables are completed cohort fertility (ctfr), intended fertility (f), and the fertility gap (gap). The explanatory variables are spendingbf, spendingbv, $\alpha, p r_{2}, \epsilon_{2}, p r_{3}$, and $p r_{3}-p r_{4}$. Moreover, we include interaction terms $\alpha^{*}$ spendingbf, $\alpha$ spendingbv, $p r_{2}{ }^{*}$ spendingbf, $p r_{2}{ }^{*}$ spendingbv, $\epsilon_{2}{ }^{*}$ spendingbf, $\epsilon_{2}{ }^{*}$ spendingbv, $\left(p r_{3}-p r_{4}\right) *$ spendingbf, and $\left(p r_{3}-p r_{4}\right) *$ spendingbv and the quadratic term $\left(p r_{3}-p r_{4}\right)^{2}$. Like in the previous estimation spendingbf and spendingbv have a significant positive impact on cohort fertility and intended fertility and a significant negative impact on the fertility gap. Fixed family allowances contribute more to the direct effect while for income dependent family allowances the direct and indirect effect are nearly equal. Homophily $\alpha$ has a significant positive impact on cohort fertility and intended fertility but no significant impact on the fertility gap. Thus, homophily operates mostly on the indirect effect. Looking at $\alpha^{*}$ spendingbf and $\alpha^{*}$ spendingbv reveals that the interaction of homophily with fixed family allowances is weakly significant, but the interaction of homophily with income dependent family allowances has a strong negative impact on cohort fertility, intended fertility, and on the fertility gap. This means, that societies characterised by a high level of homophily tend to higher levels of fertility but the role of (income dependent) policies is weaker in such societies. Network transitivity, $p r_{2}$, does not show a significant impact on any of the dependent variables and the interaction with policies is not significant either. The weight of income for calculating the social distance in equation (4), $\epsilon_{2}$, has a small but strongly significant positive impact on all three fertility measures. Thus, an increase in $\epsilon_{2}$ raises cohort fertility and intended fertility. However, the gain in intended fertility cannot be fully realised and the gap between intended and realised fertility grows. The interactions with policies, on the other hand, mitigate that effect. All coefficients have a negative sign and the negative impact of $\epsilon_{2}{ }^{*}$ spendingbv is even stronlgy significant. As expected, the probability of being positively influenced by a peer with higher parity, $p r_{3}$, has a positive impact on intended fertility. Moreover, the impact on the fertility gap is significant and negative resulting in an even stronger positive and significant impact on cohort fertility. The difference between the probabilities of being influenced by peers with higher or lower parity, $\left(p r_{3}-p r_{4}\right)$, has a strong positive impact on intended fertility and cohort fertility but also on the fertility gap. Thus, the increased intentions cannot always be met due to the budgetary contraint in our model, mitigating the positive impact on cohort fertility 
Cohort fertility vs. $\mathrm{pr}_{3}-\mathrm{pr}_{4}$

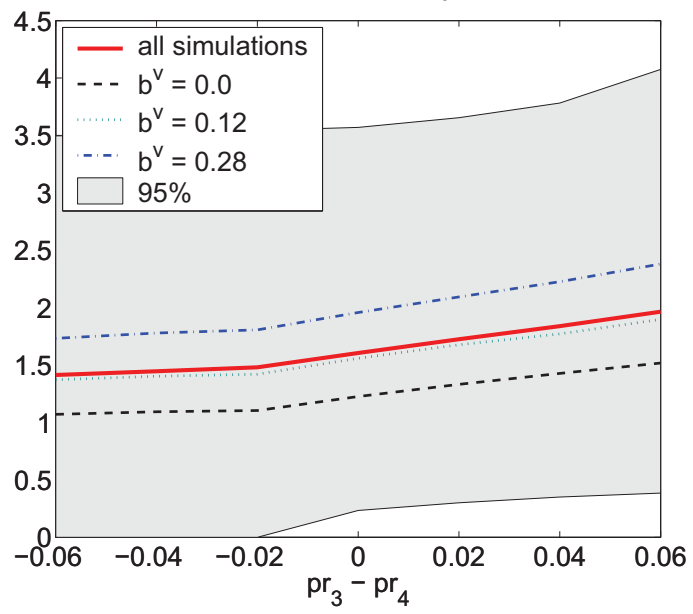

Intended fertility vs. $\mathrm{pr}_{3}-\mathrm{pr}_{4}$

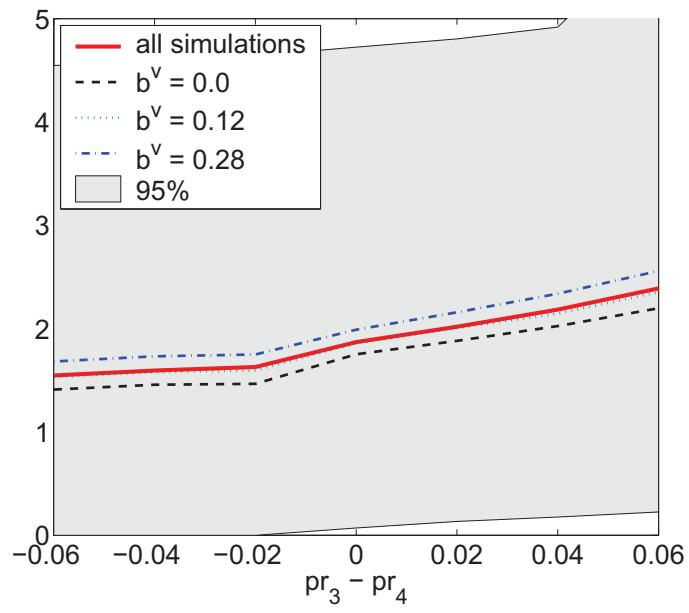

Fertility gap vs. $\mathrm{pr}_{3}-\mathrm{pr}_{4}$

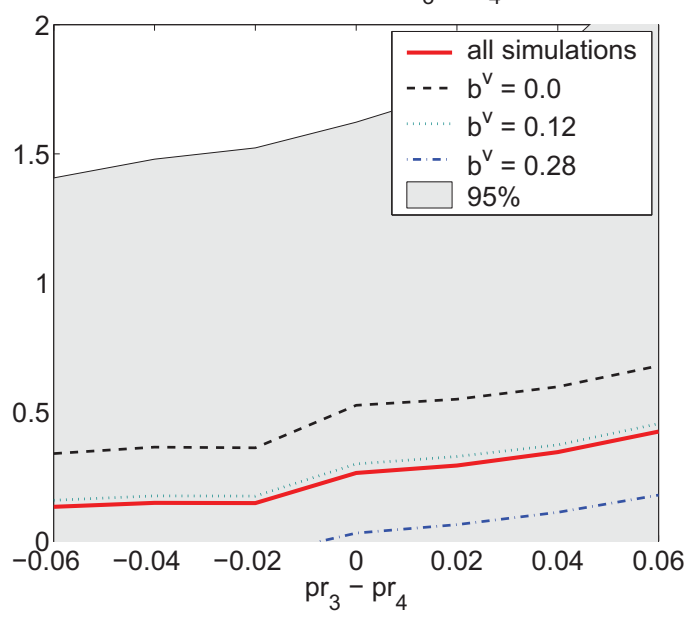

Cohort fertility vs. $\mathrm{pr}_{3}-\mathrm{pr}_{4}$

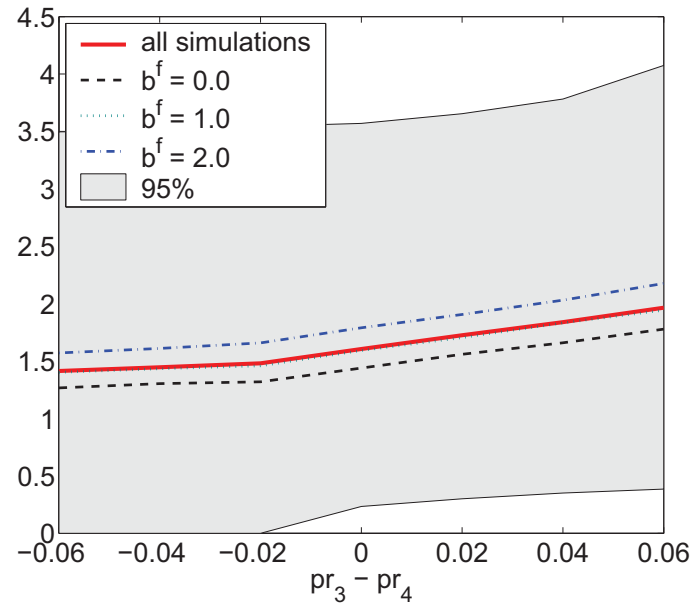

Intended fertility vs. $\mathrm{pr}_{3}-\mathrm{pr}_{4}$

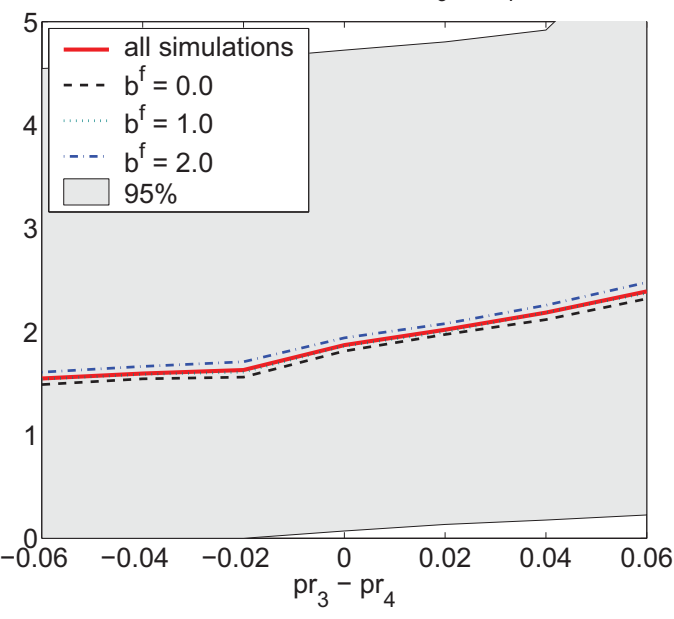

Fertility gap vs. $\mathrm{pr}_{3}-\mathrm{pr}_{4}$

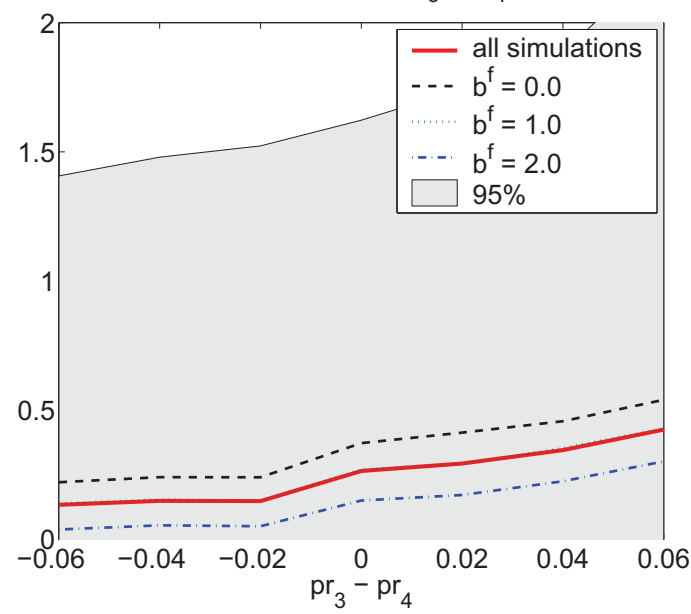

Figure 6: Completed cohort fertility, intended fertility, and fertility gap by $p r_{3}-p r_{4}$, the difference between the probabilities of positive and negative social influence and by fixed, $b^{f}$, and income dependent, $b^{v}$, family allowances. The difference has a strong positive impact on completed cohort fertility and on the fertility gap and an extremely strong positive impact on intended fertility which actually exceeds the impact of the policy mix. 


\begin{tabular}{|c|c|c|c|}
\hline $\begin{array}{l}\text { dependent } \\
\text { variable }\end{array}$ & ctfr & $\mathrm{f}$ & gap \\
\hline spendingbf & $\begin{array}{c}.1940409^{* * *} \\
(.0031738)\end{array}$ & $\begin{array}{c}.0775591^{* * *} \\
(.0049272)\end{array}$ & $\begin{array}{c}-.1164696^{* * *} \\
(.0019982)\end{array}$ \\
\hline spendingbv & $\begin{array}{c}.0735332^{* * *} \\
(.0005052)\end{array}$ & $\begin{array}{c}.0395204^{* * *} \\
(.0007843)\end{array}$ & $\begin{array}{c}-.034013^{* * *} \\
(.0003181)\end{array}$ \\
\hline$\alpha$ & $\begin{array}{c}.1243855^{* * *} \\
(.0059623)\end{array}$ & $\begin{array}{l}.129437^{* * *} \\
(.0092561)\end{array}$ & $\begin{array}{c}.0050632 \\
(.0037537)\end{array}$ \\
\hline$\alpha^{*}$ spendingbf & $\begin{array}{l}-.00779 * * \\
(.0038786)\end{array}$ & $\begin{array}{r}-.0117448^{*} \\
(.0060213)\end{array}$ & $\begin{array}{l}-.0039536 \\
(.0024419)\end{array}$ \\
\hline$\alpha^{*}$ spendingbv & $\begin{array}{c}-.0167206^{* * *} \\
(.0006116)\end{array}$ & $\begin{array}{c}-.0204917^{* * *} \\
(.0009494)\end{array}$ & $\begin{array}{c}-.0037716^{* * *} \\
(.000385)\end{array}$ \\
\hline$p r_{2}$ & $\begin{array}{l}-.0031182 \\
(.0072165)\end{array}$ & $\begin{array}{l}-.0032567 \\
(.0112033)\end{array}$ & $\begin{array}{l}-.0000995 \\
(.0045434)\end{array}$ \\
\hline $\mathrm{pr}_{2}{ }^{*}$ spendingbf & $\begin{array}{l}-.0004732 \\
(.0046968)\end{array}$ & $\begin{array}{c}.0015489 \\
(.0072916)\end{array}$ & $\begin{array}{l}.0019932 \\
(.002957)\end{array}$ \\
\hline$p r_{2}{ }^{*}$ spendingbv & $\begin{array}{l}.0002016 \\
(.000744)\end{array}$ & $\begin{array}{c}.000318 \\
(.0011551)\end{array}$ & $\begin{array}{c}.000117 \\
(.0004684)\end{array}$ \\
\hline$\epsilon_{2}$ & $\begin{array}{c}.0051561^{* * *} \\
(.0012934)\end{array}$ & $\begin{array}{c}.0095546^{* * *} \\
(.0020079)\end{array}$ & $\begin{array}{c}.0043964^{* * *} \\
(.0008143)\end{array}$ \\
\hline$\epsilon_{2}{ }^{*}$ spendingbf & $\begin{array}{l}-.0008183 \\
(.0008428)\end{array}$ & $\begin{array}{l}-.0018387 \\
(.0013084)\end{array}$ & $\begin{array}{c}-.0010213^{*} \\
(.0005306)\end{array}$ \\
\hline$\epsilon_{2}{ }^{*}$ spendingbv & $\begin{array}{c}-.0010723^{* * *} \\
(.000133)\end{array}$ & $\begin{array}{c}-.0014866^{* * *} \\
(.0002065)\end{array}$ & $\begin{array}{c}-.0004143^{* * *} \\
(.0000838)\end{array}$ \\
\hline$p r_{3}$ & $\begin{array}{c}1.997349^{* * *} \\
(.0112089)\end{array}$ & $\begin{array}{c}.2329939^{* * *} \\
(.0174013)\end{array}$ & $\begin{array}{c}-1.764388^{* * *} \\
(.0070569)\end{array}$ \\
\hline$p r_{3}-p r_{4}$ & $\begin{array}{c}4.260431^{* * *} \\
(.0516277)\end{array}$ & $\begin{array}{c}9.486284^{* * *} \\
(.0801495)\end{array}$ & $\begin{array}{c}5.226278^{* * *} \\
(.0325037)\end{array}$ \\
\hline$\left(p r_{3}-p r_{4}\right)^{2}$ & $\begin{array}{c}20.89095^{* * *} \\
(.585272)\end{array}$ & $\begin{array}{c}32.61836^{* * *} \\
(.9086058)\end{array}$ & $\begin{array}{c}11.7265^{* * *} \\
(.3684751)\end{array}$ \\
\hline$\left(p r_{3}-p r_{4}\right)^{*}$ spendingbf & $\begin{array}{c}.4146195^{* * *} \\
(.0334119)\end{array}$ & $\begin{array}{c}.0772179 \\
(.0518703)\end{array}$ & $\begin{array}{c}-.3374474^{* * *} \\
(.0210354)\end{array}$ \\
\hline$\left(p r_{3}-p r_{4}\right)^{*}$ spendingbv & $\begin{array}{c}-.0200548^{* * *} \\
(.0053607)\end{array}$ & $\begin{array}{c}-.2432559 * * * \\
(.0083222)\end{array}$ & $\begin{array}{c}-.2232603^{* * *} \\
(.003375)\end{array}$ \\
\hline Adjusted $R^{2}$ & 0.1436 & 0.0504 & 0.1350 \\
\hline
\end{tabular}

Table 2: Estimation of the impact of family allowances and parameters determining the social structure on completed cohort fertility, intended fertility, and the fertility gap, standard errors in parentheses, ${ }^{*}$ significant at 10 percent; ** significant at 5 percent; $* * *$ significant at 1 percent. 
compared to intended fertility. The quadratic term $\left(p r_{3}-p r_{4}\right)^{2}$ has an even stronger positive impact on the three dependent variables, confirming the results depicted in figure 6 . The interaction $\left(p r_{3}-p r_{4}\right)^{*}$ spendingbf has a significant positive impact on completed cohort fertility, no significant impact on intended fertility and a significant negative impact on the fertility gap. Thus, the difference $\left(p r_{3}-p r_{4}\right)$ supports the direct effect of fixed family allowances resulting in higher cohort fertility. The interaction with income dependent family allowances, $\left(p r_{3}-p r_{4}\right)^{*}$ spendingbv, has a significant negative impact on cohort fertility, intended fertility, and on the fertility gap. Hence, the difference $\left(p r_{3}-p r_{4}\right)$ strengthens the direct effect of income dependent family allowances but weakens its indirect effect resulting in a negative impact on cohort fertility.

\section{Summary and conclusions}

We study the impact of fixed and income dependent family allowances on intended fertility, on the realisation of intended fertility and on the resulting completed cohort fertility. In particular we investigate whether the structure of a society represented by parameters specifying the social network and the social influence mechanism has the potential to alter the role of family policies. In our modelling framework individuals are characterised by their sociodemographic characteristics age, household income, parity, the number of dependent children, and intended fertility. The agents are closely linked to a set of other agents with whom they communicate about their fertility intentions and realisations. We refer to this group as an agent's social network. The whole agent population constitutes the society. The agents are not directly linked to those agents who do not belong to their social network but any agent may somehow indirectly influence any other agent via intermediaries. The above mentioned characteristics as well as family policy measures and the social influence exerted by the social network have an impact on the agent's fertility intentions and behaviour. The model allows us to carry out experiments to test various combinations of childcare benefits and combine them with different assumptions regarding the underlying social structure.

Our simulations reveal a positive impact of both fixed and income dependent family allowances on completed cohort fertiliy and on intended fertility and a negative impact of fixed and income dependent child supports on the fertility gap. However, several network and social influence parameters have the ability not only to influence fertility itself but also to influence the effectivity of family policies, often in a detrimental way. For instance, while a higher degree of homophily among the network partners has a positive effect on fertility (intentions and realisations), family policies may be less effective in such a society. A similar result holds for the parameter that characterises the weight put on income in the selection of the social network and the parameter that determines the social influence on intended fertility among network partners. Therefore, policymakers aiming to transfer a certain policy mix that has proved successful from one country to another one ignoring differences in the social structure may fail. Family policies can only be successful if they explicitly 
take into account the characteristics of the society they are assigned for.

We further conclude that empirical cross-country comparisons of different types of family policies need to be interpreted with caution for two reasons. Firstly, the empirical impact of a certain policy depends on the subset of policies being investigated and comprehensive experiments taking into consideration any possible policy mix are not feasible in the real world. Secondly, many empirical studies do not account for differences in the social structure in the countries under consideration. 


\section{References}

Aparicio Diaz, B., Fent, T., Prskawetz, A., and Bernardi, L. (2007). Transition to parenthood: The role of social interaction and endogenous networks. VID Working Paper 05/2007, Vienna Institute of Demography, Austrian Academy of Sciences.

Baroni, E., Eklöf, M., Hallberg, D., Lindh, T., and Žamac, J. (2009). Fertility decisions - simulation in an agent-based model (IFSIM). In Zaidi, A., Harding, A., and Williamson, P., editors, New Frontiers in Microsimulation Modelling, volume 36 of Public Policy and Social Welfare, pages 265-286. European Centre Vienna, Ashgate.

Bernardi, L. (2003). Channels of social influence on reproduction. Population Research and Policy Review, 22:527-555.

Billari, F. C., Aparicio Diaz, B., Fent, T., and Prskawetz, A. (2007). The "weddingring": An agent-based marriage model based on social interaction. Demographic Research, 17(3):59-82.

Björklund, A. (2006). Does family policy affect fertility? Lessons from Sweden. Journal of Population Economics, 19(1):3-24.

Bühler, C. and Philipov, D. (2005). Social capital related to fertility: Theoretical foundations and empirical evidence from bulgaria. Vienna Yearbook of Population Research, 3:53-81.

Dunbar, R. and Spoors, M. (1995). Social networks, support cliques, and kinship. Human Nature, 6(3):273-290.

Fernandez, R. and Fogli, A. (2006). Fertility: The role of culture and family experience. Journal of the European Economic Association, 4(2-3):552-556.

Feyrer, J., Sacerdote, B., and Stern, A. D. (2008). Will the stork return to Europe and Japan? understanding fertility within developed nations. Journal of Economic Perspectives, 22(3):3-22.

Gauthier, A. H. (2007). The impact of family policies on fertility in industrialized countries: a review of the literature. Population Research and Policy Review, 26(3):323-346.

Gauthier, A. H. and Hatzius, J. (1997). Famliy, benefits and fertility: an econometric analysis. Population studies, 51(3):295-306.

Goldenberg, J., Libai, B., Moldovan, S., and Muller, E. (2007). The NPV of bad news. International Journal of Research in Marketing, 24:186--200.

Goldstein, J., Sobotka, T., and Jasilioniene, A. (2009). The end of "lowest-low" fertility? Population and Development Review, 35(4):663-699. 
Kohler, H.-P., Billari, F. C., and Ortega, J. A. (2002). The emergence of lowestlow fertility in Europe during the 1990s. Population and Development Review, 28(4):641-680.

Leridon, H. (2004). Can assisted reproduction technology compensate for the natural decline in fertility with age? A model assessment. Human Reproduction, 19(7):1549-1554.

Leridon, H. (2008). A new estimate of permanent sterility by age: Sterility defined as the inability to conceive. Population Studies, 62(1):15-24.

McDonald, P. (2006). Low fertility and the state: The efficacy of policy. Population and Development Review, 32(3):485-510.

Myrskylä, M., Kohler, H.-P., and Billari, F. (2008). Human development and low fertility. European Population Conference, Barcelona, Spain.

Philipov, D., Spéder, Z., and Billari, F. C. (2006). Soon, later, or ever? the impact of anomie and social capital on fertility intentions in bulgaria (2002) and hungary (2001). Population Studies, 60(3):289-308.

Simao, J. and Todd, P. M. (2003). Emergent patterns of mate choice in human populations. Artificial Life, 9:403-417.

Todd, P. M. and Billari, F. C. (2003). Population-wide marriage patterns produced by individualmate-search heuristics. In Billari, F. C. and Fürnkranz, A., editors, Agent-based computational demography, pages 117-137, Berlin. Springer-Verlag.

Todd, P. M., Billari, F. C., and Simao, J. (2005). Aggregate age-at-marriage patterns from individual mate search heuristics. Demography, 42. 


\section{VIENNA INSTITUTE OF DEMOGRAPHY}

\section{Working Papers}

Buber, Isabella, Caroline Berghammer, and Alexia Prskawetz, Doing Science, Forgoing Childbearing? Evidence from a Sample of Female Scientists in Austria, VID Working Paper 01/2011.

Strulik, Holger, Klaus Prettner, and Alexia Prskawetz, R\&D-Based Growth in the Post-Modern Era, VID Working Paper 09/2010.

Prettner, Klaus and Alexia Prskawetz, Demographic Change in Models of Endogenous Economic Growth. A Survey, VID Working Paper 08/2010.

Flandorfer, Priska, Christian Wegner, and Isabella Buber, Gender Roles and Smoking Behaviour, VID Working Paper 07/2010.

Barakat, Bilal, Johannes Holler, Klaus Prettner, and Julia Schuster, The Impact of the Economic Crisis on Labour and Education in Europe, VID Working Paper 06/2010.

Grafeneder-Weissteiner, Theresa and Klaus Prettner, Agglomeration Processes in Ageing Societies, VID Working Paper 05/2010.

Buber, Isabella, Parity-specific weights for the Austrian Generations and Gender Survey, VID Working Paper 04/2010.

Testa, Maria Rita, She wants, he wants: Couple's childbearing desires in Austria, VID Working Paper 03/2010.

Buber, Isabella, Wissenschaftlerinnen in Österreich - Zusatzerhebung im Rahmen des GGS.Dokumentation der Datenerhebung und deskriptive Ergebnisse, VID Working Paper 02/2010.

Kuhn, Michael, Stefan Wrzaczek, Alexia Prskawetz, and Gustav Feichtinger, Externalities in a Life-Cycle Model with Endogenous Survival, VID Working Paper 01/2010.

Prettner, Klaus, Population Ageing and Endogenous Economic Growth, VID Working Paper 08/2009.

Št’astná, Anna and Tomáš Sobotka, Changing Parental Leave and Shifts in Second and Third-Birth Rates in Austria, VID Working Paper 07/2009.

Prettner, Klaus and Alexia Prskawetz, Decreasing Fertility, Economic Growth and the Intergenerational Wage Gap, VID Working Paper 06/2009.

The Vienna Institute of Demography Working Paper Series receives only limited review. Views or opinions expressed herein are entirely those of the authors. 